\title{
Relação Médico-Paciente e Relação Perito-Periciando: diferenças e semelhanças
}

\author{
Physician-Patient Relationship and Examiner-Patient \\ Relationship: differences and similarities
}

\author{
Ângela Tartuce Gomes da Silva ${ }^{1}$, Daniele Pimentel Maciel ${ }^{2}$, \\ Valéria M. S. Framil ${ }^{3}$, Daniele Muñoz Gianvecchio ${ }^{4}$, \\ Victor A. P. Gianvecchios, Daniel Romero Muñoz ${ }^{6}$
}

DOI: http://dx.doi.org/10.11606/issn.2317-2770.v22i1p50-55

\begin{abstract}
Silva ATG, Maciel DP, Framil VMS, Gianvecchio DM, Gianvecchio VAP, Muñoz DR. Relação Médico-Paciente e Relação Perito-Periciando: diferenças e semelhanças. Saúde, Ética \& Justiça. 2017;22(1):50-5.

RESUMO: Introdução: A relação médico-paciente é a base da Medicina e está fundamentada nos princípios da beneficência, não-maleficência, justiça e autonomia. A perícia médica surgiu diante da necessidade da aplicação de conhecimentos técnicos no âmbito do Direito. As diferenças entre essas duas atuações médicas é objeto de conflitos que dificultam a atuação do médico perito. Objetivo: Estabelecer as diferenças e semelhanças entre a relação médico-paciente e a relação perito-periciando. Material e Métodos: Revisão de literatura de artigos e periódicos em língua portuguesa na base de dados Scielo e em livros especializados sobre o assunto. Discussão: A relação médico-paciente se baseia em confiança mútua, estabelecimento de vínculo mútuo, busca por um resultado em comum: diagnóstico e tratamento; há coerência entre a comunicação verbal e não verbal, a anamnese constitui o principal método propedêutico, sendo os exames complementares solicitados para auxiliar o diagnóstico e há o compromisso com o sigilo profissional. Já a relação peritopericiando possui uma natureza investigativa, não havendo uma relação de confiança mútua, a finalidade é o esclarecimento da Justiça e o sigilo profissional não fica restrito ao binômio perito-periciando. A semelhança entre essas duas relações está relacionada à conduta do médico que deve ser pautada na técnica, no respeito, educação e abstenção de julgamentos morais e de valores, além da necessidade de atualização por parte do profissional. Conclusão: A relação médico-paciente e a relação perito-periciando apresentam características peculiaridades e algumas delas são inconfundíveis. Em ambas as situações observamos a importância da atuação médica como essência desta relação e suas consequentes implicações morais, jurídicas e éticas.
\end{abstract}

DESCRITORES: Relação Médico-Paciente; Jurisprudência; Prova Pericial.

\footnotetext{
1. Médica Pediatra; Pós-graduada em Perícia Médica pela Faculdade de Ciências Médicas da Santa Casa de São Paulo FCMSCSP.

2. Médica do trabalho e Perita na Justiça do Trabalho. Professora convidada do Curso de pós-graduação em Perícias Médicas da Faculdade de Ciências Médicas da Santa Casa de São Paulo.

3. Mestre pela Universidade de São Paulo; Doutora pela Faculdade de Ciências Médicas da Santa Casa de São Paulo. Professora convidada do Curso de pós-graduação em Perícias Médicas da Faculdade de Ciências Médicas da Santa Casa de São Paulo.

4. Médica Perita do INSS. Professora convidada do Curso de pós-graduação em Perícias Médicas da Faculdade de Ciências Médicas da Santa Casa de São Paulo.

5. Médico Legista do IML/SP; Professor de Medicina Legal e Bioética da Faculdade de Ciências Médicas da Santa Casa de São Paulo; Professor de Medicina Legal e Ética Profissional da Universidade Anhembi Morumbi.

6. Professor Titular de Medicina Legal, Medicina do trabalho e Bioética da Faculdade de Medicina da USP.

Endereço para correspondência: Daniele Muñoz Gianvecchio. E-mail: danimunoz@uol.com.br
} 


\section{INTRODUÇÃO}

$\mathbf{O}$ primeiro Código de Ética Médica para médicos foi elaborado por Hipócrates, nascido na Ilha de Cós (460 -377 a.C.).

Sua obra "Juramento" continha todas as regras a serem obedecidas por aqueles que iniciavam a vida profissional como médicos. Estes princípios propostos por Hipócrates perduram até os dias de hoje como atribuições imprescindíveis da atuação médica ${ }^{1}$. No juramento hipocrático são citados os princípios básicos da Medicina como: o profissional médico ter habilitação legal e conduta ética para o exercício da Medicina; os princípios da beneficência e da não-maleficência; o compromisso do sigilo profissional que o médico tem para com seu paciente e os deveres de conduta do médico para evitar a culpa stricto sensu: a negligência, a imprudência e a imperícia ${ }^{1-3}$.

No Brasil, o Código de Ética Médica, revisado em 2009 de acordo com a Resolução CFM No 1.931, de 17 de setembro de $2009^{4}$, apresenta, no seu preâmbulo:

\begin{abstract}
"O presente Código de Ética Médica contém as normas que devem ser seguidas pelos médicos no exercício de sua profissão, inclusive no exercício de atividades relativas ao ensino, 'a pesquisa e à administração de serviços de saúde, bem como no exercício de quaisquer outras atividades em que stricto sensu se utilize o conhecimento advindo do estudo da Medicina. " (s/n).
\end{abstract}

Flamínio Fávero afirmava que "a Medicina é uma arte" referindo-se à delicada interação humana na prática médica, o alicerce da Medicina que é a relação médicopaciente $^{1}$. De acordo com Edmund Pellegrino (apud Pessini) "a relação médico-paciente é uma equação moral marcada pela reciprocidade com direitos e obrigações tanto do lado do paciente quanto do médico. Deve ser equilibrada de forma que ambos busquem o bem um do outro e se respeitem em suas autonomias"5.

A Relação Médico Paciente tem como elemento fundamental, para o bom desenvolvimento da relação, a confiança ${ }^{6}$. Essa interação constitui a base da prática clínica no dia-a-dia do médico ${ }^{1}$ e, no decorrer da história da Medicina, a relação médico-paciente tem passado por inúmeras transformações, desde o modelo biomédico paternalista até o modelo biopsicossocial, que preconiza a humanização do atendimento, não deixando de salientar a confiança e a cooperação mútua entre médicos e pacientes ${ }^{3}$.

Em contrapartida, a perícia médica surgiu diante da necessidade da aplicação dos conhecimentos médicos, técnicos e científicos, aos casos do Direito, no sentido de produzir provas e auxiliar o juízo na busca da verdade dos fatos para que a justiça seja feita. Os primeiros relatos de perícia médica datam do antigo Império Romano. Devido à natureza investigativa e seu contexto judicial, a relação perito-periciando, diferentemente da relação médicopaciente, é conflituosa desde o início e não se baseia na confiança e colaboração recíproca ${ }^{7}$.

A importância da perícia médica no âmbito judiciário pode ser percebida pelo trabalho realizado pelo Instituto de Pesquisa Econômica Aplicada (IPEA) a pedido do Conselho de Estudos Judiciários (CEJ) e do Conselho da Justiça Federal (CJF), publicado sob o título Acesso à Justiça Federal: dez anos de juizados especiais $(\mathrm{JEF})^{2,8}$. Segundo esse levantamento, a demanda por perícias médicas nos Juizados Especiais Federais é elevada, sendo a perícia médica realizada em 90,4\% das ações movidas por auxílio-doença e em 90,9\% das ações por aposentadoria por invalidez ${ }^{8}$. Esse trabalho também evidenciou alguns entraves relacionados à perícia médica que contribuem para a dificuldade de compreensão do âmbito de atuação do médico perito. Dentre esses fatores, destacam-se a dificuldade em se distinguir a finalidade da perícia médica, realizada pelo perito, da consulta médica assistencial, tanto por parte dos usuários e seus acompanhantes, advogados, como pelos servidores dos juizados ${ }^{8}$. $\mathrm{O}$ autor destaca que:

\begin{abstract}
"O desconhecimento sobre os procedimentos das perícias, aliado à desinformação sobre o beneficio reivindicado, gera ansiedade nas partes, que buscam obter informações cruzadas com outras pessoas que estão vivenciando a mesma situação. Enquanto aguardam na sala de espera, que em alguns juizados, chega a se assemelhar à de um ambulatório público, comparam suas demandas com outras pessoas e ficam inconformados quando o desenlace de uma e de outra é diferente. Há ainda a expectativa de que a perícia ocorra de forma análoga a uma consulta médica"s.
\end{abstract}

Assim, apesar do posicionamento dos participantes de ambas as relações estarem polarizados, com o médico em um polo e um indivíduo doente em outro polo, existe um razoável desconhecimento quanto à interpretação destas duas atividades médicas. A carência de compreensão da natureza essencial da atuação do médico assistente e do perito médico, por parte de alguns profissionais de saúde, bem como advogados e outros profissionais ligados ao Direito, além do maior interessado na perícia, ou seja, o periciando, representa uma significativa origem de inúmeros problemas ${ }^{9}$. Desta forma, o presente estudo tem por objetivo analisar as diferenças e semelhanças entre a relação médico-paciente e a relação perito-periciando e auxiliar a esclarecer dúvidas sobre as características peculiares dessas relações.

\section{MÉTODOS}

A metodologia utilizada foi uma revisão bibliográfica de literatura nacional utilizando a base de dados Scielo para a busca de artigos publicados no 
período de 2009 a 2016. Para a pesquisa, foram utilizados os termos: "relação médico paciente", "perícia médica", "medicina assistencial", "empatia médica" e "modelo biomédico". Também foram utilizados livros jurídicos especializados na relação perito-periciando.

\section{Critérios de Inclusão}

Estudos da literatura nacional, publicados no período de janeiro de 2009 a julho de 2016, foram incluídos com as seguintes características: estudos que analisam a relação médico-paciente no âmbito da atenção primária à saúde em que há prática médica extrahospitalar, em instituições, consultórios e clínicas no âmbito privado e da rede assistencial pública, em centros de saúde e ambulatórios.

\section{Critérios de Exclusão}

Os estudos que foram excluídos apresentavam situações que não caracterizavam estritamente a relação médico-paciente, como: trabalhos sobre Programa de Saúde da Família (PSF), na área de pediatria, na área da urgência e emergência, casos de iatrogenia, erro médico, em pacientes terminais ou em estado crítico, pacientes da graduação médica e os artigos de caráter estritamente jurídico, psicossocial ou religioso.

\section{RESULTADOS}

As publicações na sua grande maioria versam sobre a relação médico-paciente e, na prática pericial, essa relação passa a ser denominada relação peritopericiando por possuir aspectos bastante característicos. Suas publicações são escassas e algumas controversas.

A Tabela 1 demonstra as diferenças e as semelhanças entre a relação médico-paciente e a relação perito-periciando, de acordo com o que está descrito na literatura.

Tabela 1. Diferenças e semelhanças entre a relação médico-paciente e a relação médico-periciando

\begin{tabular}{|c|c|c|}
\hline & \multicolumn{2}{|c|}{ RELAÇÃO MÉDICO } \\
\hline & PACIENTE & PERICIANDO \\
\hline \multirow[t]{11}{*}{ DIFERENÇAS } & Confiança & Não há confiança mútua \\
\hline & Cooperação & Relação conflituosa \\
\hline & Princípios: & Princípios: \\
\hline & Beneficência & Equidade e Justiça Social \\
\hline & Não-maleficência & Não se aplicam os principios: \\
\hline & Autonomia & beneficência, não-maleficência e autonomia \\
\hline & Objetivo: & Objetivo: \\
\hline & Terapêutica & Produzir provas \\
\hline & Compromisso com o paciente & Compromisso com a Justiça \\
\hline & Sigilo profissional & Dever legal de prestar \\
\hline & & esclarecimento ao juízo \\
\hline \multirow[t]{10}{*}{ SEMELHANÇAS } & Respeito, cordialidade, livre de & Respeito, cordialidade, livre \\
\hline & de preconceitos sociais e julga- & de preconceitos sociais e julga- \\
\hline & mentos morais & mentos morais \\
\hline & Autoridade médica para o & Autoridade médica para correta \\
\hline & sucesso terapêutico & avaliação pericial \\
\hline & Médico sempre atualizado & Médico sempre atualizado \\
\hline & Abster-se de abusos & Abster-se de abusos \\
\hline & Oferecer todas as informações & Oferecer todas as informações \\
\hline & sobre o diagnóstico e a terapêutica & sobre finalidade da perícia médica \\
\hline & Manter qualidade do trabalho & Manter qualidade do trabalho \\
\hline
\end{tabular}




\section{DISCUSSÃO}

Diferenças entre a relação médico-paciente e a relação perito-periciando

A relação médico-paciente tem como características fundamentais a confiança e a cooperação mútua em prol do restabelecimento da saúde do paciente, que é o objetivo comum ${ }^{3,9}$. Atende aos princípios da beneficência, da não-maleficência, da autonomia do paciente e ao princípio constitucional que define a saúde como direito universal de todos e dever do Estado ${ }^{3,10}$. O médico é visto como um amigo e o objetivo de uma consulta médica é obter uma anamnese e exame físico adequados, a fim de auxiliar na busca por um diagnóstico preciso e uma terapêutica mais eficiente, capaz de trazer alívio para a dor e sofrimento do paciente ${ }^{3}$. A satisfação do paciente é diretamente proporcional à cura dos seus males, sendo este o ganho primário da relação médicopaciente, podendo ter ganhos secundários, geralmente de natureza emocional, como atenção e cuidado, que mobilizam toda a família do paciente ${ }^{3}$.

A relação perito-periciando é de natureza investigativa e não há cooperação entre perito e periciando9. É conflituosa, pois não há um objetivo comum. Enquanto o perito procura fazer justiça social, o periciando visa uma perícia sempre favorável ao seu caso $^{3,9}$. O objetivo do diagnóstico médico na perícia não é instituir tratamentos, e sim esclarecer e auxiliar o juízo na sua decisão com a finalidade de fazer a justiça social ${ }^{3,10}$. A perícia se destina a produzir provas, baseadas em fatos e dados objetivos, que podem ou não gerar direitos para o periciando, perante o juízo ${ }^{9}$. A relação perito-periciando atende aos princípios da veracidade, equidade e justiça, não se aplicando os princípios da beneficência, nãomaleficência e autonomia do periciando, uma vez que pressupõe que o mesmo esteja pleiteando algum tipo de indenização ou benefícios ${ }^{3,10,11}$.

Na relação médico-paciente, a empatia médica e a efetiva comunicação, verbal e não verbal, são elementos fundamentais para o estabelecimento do vínculo entre médico e paciente e o sucesso terapêutico ${ }^{11,12}$.

A autonomia do paciente e o paternalismo do médico na relação-médico paciente são caracterizadas por uma dualidade, representada como uma figura de um pêndulo, onde de um lado há uma relação absolutamente autônoma e, do outro, uma relação com o predomínio do paternalismo, construindo uma relação totalmente assimétrica. A autonomia e o paternalismo são complementares e ambos, médico e paciente, necessitam encontrar um ponto ideal de equilíbrio ${ }^{12-14}$.

$\mathrm{Na}$ relação médico-paciente os exames complementares auxiliam no diagnóstico, porém a anamnese se mostra mais efetiva como método propedêutico, assim como o exame físico detalhado ${ }^{15,16}$.
$\mathrm{Na}$ relação perito-periciando, em muitos casos, a documentação trazida pelo periciando como atestados, relatórios, prontuários, receitas, exames complementares são as únicas fontes de informações sobre o caso e, dependendo da sua origem, nem sempre fidedignas, devendo ser analisadas pelo perito com critério e cautela $^{15,16}$. O exame físico apurado é primordial para que o perito possa concluir o seu laudo pericial ${ }^{15,16}$.

Na relação médico-paciente, o médico assistente está totalmente compromissado com o seu doente, é a fidelidade profissional em benefício do paciente, deve manter sigilo de todas as informações a que tiver acesso a respeito do seu paciente ${ }^{16-18}$. A quebra do sigilo só se justifica por justa causa, dever legal ou se houver consentimento por escrito do próprio paciente ${ }^{15-17}$. O médico assistente se manifesta através de atestados, relatórios e prontuários médicos que são privativos do paciente ${ }^{15-17}$.

$\mathrm{Na}$ relação perito-periciando, o médico perito está totalmente compromissado com a Justiça e o sigilo profissional não é uma obrigatoriedade absoluta para o perito, que tem o compromisso legal de prestar informações à Justiça, ou seja, o conteúdo da perícia não fica reservado ao binômio perito periciando ${ }^{3,12}$. É dever do perito prestar todos os esclarecimentos necessários em juízo, estando de acordo com o artigo 73 do Código de Ética Médica ${ }^{19}$, sem o risco de incorrer em infração ética. $\mathrm{O}$ perito médico se manifesta através de laudos periciais e pareceres que são públicos, a não ser que, por determinação judicial, devam permanecer em segredo de justiça $\mathrm{a}^{3,12}$.

\section{Semelhanças entre a relação médico-paciente e a relação perito-periciando}

Considerarquearelaçãomédico-pacienteearelação perito-periciando são absolutamente inconfundíveis não significa que sejam totalmente distintas, na verdade, as duas relações apresentam algumas similitudes.

Alguns atributos relativos aos médicos estão presentes em ambas, como: respeito, educação, cordialidade, abster-se de julgamentos morais ou preconceitos sociais, agir com responsabilidade, isenção de ânimo e paciência, ter autonomia e autoridade no desempenho de suas funções e ser assertivo sempre. A autoridade médica é fundamental para o sucesso terapêutico na medicina assistencial e para a correta avaliação do periciando durante a perícia ${ }^{3}$.

Os sujeitos da relação são os mesmos, médicos de um lado e examinados do outro. As duas relações e todos os seus desdobramentos são atos médicos, portanto os deveres de conduta são os mesmos para o médico assistente ou perito médico: manter-se atualizado, ser vigilante em relação ao paciente e ao periciando, abster-se de abusos e dar todas as informações e esclarecimentos devidos, 
ou consentimento informado, lembrando que o médico assistente presta esclarecimentos sobre o diagnóstico e o tratamento indicado e o médico perito esclarece sobre a finalidade da perícia médica e o respectivo processo judicial sem fazer diagnósticos ou dar resultados ao periciando ${ }^{14}$. Desta forma, qualquer dano que venha a ocorrer seja por negligência, imprudência ou imperícia, submete tanto o médico assistente quanto o perito às sanções penais, cíveis e éticas ${ }^{14}$.

Um problema atual que se configura como outro fator em comum entre o médico assistente e o médico perito é o possível comprometimento da dinâmica e da qualidade do seu trabalho em função da excessiva carga de atendimentos diários, seja no contexto assistencial, com interferência dos convênios ou muitos locais de trabalho no dia-a-dia do médico, e no contexto pericial, com interferência de uma autarquia nos casos previdenciários e grande afluxo de litígios em alguns órgãos judiciais ${ }^{2,4}$.

\section{CONCLUSÃO}

A relação médico-paciente e a relação peritopericiando apresentam suas características peculiares e observamos em ambas as situações a figura do médico como um mediador e suas consequentes implicações morais, jurídicas e éticas.

Os dois tipos de relacionamento apresentam tanto semelhanças quanto as suas diferenças. Como semelhanças, tanto na relação médico-paciente quanto na relação perito-periciando temos presente a figura de dois autores principais: de um lado a presença do médico que detém o conhecimento e, do outro, a figura do paciente/ periciando com uma situação delicada a se resolver. Já, as diferenças serão pautadas nos objetivos destas relações. $\mathrm{Na}$ relação médico-paciente o objetivo é a busca pelo tratamento e cura de uma doença, consequentemente haverá a construção de uma cumplicidade que fortalece o vínculo de confiança entre ambos. Na relação médico-periciando, o objetivo é o esclarecimento da justiça através de um exame de natureza médica e da análise de documentos, determinado por uma autoridade e cujo desfecho pode ter um impacto importante na vida do periciando. Uma situação difícil, na qual o médico perito e o periciando não compartilham os mesmos interesses. O médico perito compromissado com a justiça e o periciando interessado, apenas, num posicionamento a seu favor. Desta forma, conseguimos compreender tanto as semelhanças quanto as diferenças entre as relações estudadas.

Silva ATG, Maciel DP, Framil VMS, Gianvecchio DM, Gianvecchio VAP, Muñoz DR. Physician-Patient Relationship and Examiner-Patient Relationship: differences and similarities. Saúde, Ética \& Justiça. 2017;22(1):50-5.

\begin{abstract}
Introduction: Physician-patient relationship is the basis of Medicine. It is founded on the principles of beneficence, non-maleficence, justice, and autonomy. The field of legal medical developed from the need to apply technical knowledge to assist legal processes. The differences between these two medical practices are at the origin of conflicts that hinder the performance of the medical examiner. Objective: To establish the differences and similarities between the physician-patient relationship and the -examiner-patient relationship. Methods: Literature review of articles and journals in Portuguese in Scielo databases and in specialized books on the subject. Discussion: Physician-patient relationship is based on mutual trust and mutual bond; the physician and patient both seek for diagnosis and treatment; there is consistency between verbal and nonverbal communication; establishing the case history is the main diagnostic method, while further tests are requested to assist the diagnosis; and there is a commitment to professional secrecy. The examiner-patient relationship has an investigative nature; it is not based on mutual trust; the purpose is to assist Court decisions by clarifying medical aspects of the case; and professional confidentiality is not restricted to the examiner-patient binomial. The similarity between these two relations is seen in the physician's conduct, which must always be based on technique, respect, appropriate behavior, a non-judgmental approach, and also being up to date on professional advances . Conclusion: The Patient-Physician Relationship and the Patient-Examiner Relationship have peculiarities and some of them are unmistakable. In both situations, we observe the importance of medical practice as the essence of this relationship and its consequent moral, legal, and ethical implications.
\end{abstract}

KEY WORDS: Physician-Patient Relations; Jurisprudence; Expert Testimony.

\title{
REFERÊNCIAS
}

1. Miziara ID, Munõz DR. Aspectos éticos e legais do atendimento médico. In: Condutas em clínica médica. $1^{\text {a }}$ ed. São Paulo: Editora Atheneu; 2014. p.1157-72.

2. Neto MK. Responsabilidade civil do médico. São Paulo: RT; 2013.
3. Almeida EHR. Aspectos bioéticos da perícia médica previdenciária. Rev Bioét. 2011;19(1):277-98.

4. Conselho Federal de Medicina (CFM). Revisão do Código de Ética Médica [Internet]. Brasília; 2010 [acesso em 2016 fev. 05]. Disponível em: http://www.rcem.cfm.org.br/index. 
php/cem-atual

5. Pessini L. Problemas atuais de bioética. São Paulo: Edições Loyola; 2001.

6. Bergstein G. A informação na relação médico-paciente. $1^{\text {a }}$ ed. São Paulo: Editora Saraiva; 2013.

7. Marçal H. Médico perito: uma especialidade reconhecida [Internet]. Brasília; 2012 [2013 jan. 02; acesso em 2016 fev. 13]. Disponível em: http://portal.cfm.org.br/index. php?option $=$ com_content $\&$ view $=$ article $\&$ id $=23470$ :medic o-perito-uma-especialidadereconhecida\&catid=46:artigos \&Itemid $=18$

8. Instituto de Pesquisa Econômica Aplicada (IPEA). Acesso à Justiça Federal: dez anos de juizados especiais. Brasília: Conselho da Justiça Federal, Centro de Estudos Judiciários; 2012.

9. Barros Junior EA. Direito previdenciário médico: a relação médico periciado. São Paulo: Editora Atlas; 2010.

10. Lise MLZ, El Jundi SARJ, Silveira JUG, Coelho RS, Ziulkoski LM. Isenção e autonomia na perícia médica previdenciária no Brasil. Rev Bioét. 2013;21(1):67-74.

11. Soar Filho EJ. Comunicação: a interação médico-cliente. Rev Ass Med Brasil. 1998;44(1):35-42.

12. Ballester D, Zuccolotto SMC, Gannam SSA, Escobar AMU. A inclusão da perspectiva do paciente na consulta médica: um desafio na formação do médico. Rev Bras Educ Méd. 2010;34(4):598-606.

13. Sicoli LF. Perícia médica: a convergência entre a medicina e o direito [Internet]. Brasília; 2012 [acesso em $2016 \mathrm{fev}$ 13]. Disponível em: http://www.administradores.com.br/ artigos/negocios/pericia-medica-a-convergencia-entre-amedicina-e-o-direito/61096/

14. Barbosa L, Diniz D, Santos W. Diversidade corporal e perícia médica: novos contornos da deficiência para o benefício de prestação continuada. Revista Textos \& Contextos Porto Alegre. 2009;8(2):377-90.

15. Loch JA. Confidencialidade: natureza, características e limitações no contexto da relação clínica. Rev Bioét. 2003;11(1):51-64.

16. Barletta JB, Gennari MS, Cipolotti R. A perspectiva cognitivo- comportamental dos aspectos psicossociais que interferem na qualidade da relação médico-paciente. Psicol Rev. 2011;17(3):396-413.

17. Aguiar P, Salgueira A, Frada T, Costa MJ. Empatia médica: tradução, validação e aplicação de um instrumento de medição. In: Actas do X Congresso Internacional GalegoPortuguês de Psicopedagogia; 2009; Braga (Portugal). Braga: Universidade do Minho; 2009. p.3705-16.

18. Marques Filho J, Hossne WS. A relação médico-paciente sob a influência do referencial bioético da autonomia. Rev Bioét. 2015;23(2):304-10. DOI: http://dx.doi. org/10.1590/1983-80422015232069

19. Dantas E, Coltri E. Capítulo IX - Sigilo profissional. In: Comentários ao Código de Ética Médica. $2^{\mathrm{a}}$ ed. Rio de Janeiro: Editora GZ; 2012. p.297-322.

Recebido para publicação: 06/08/2015

Aceito para publicação: 23/03/2017 